\title{
Avaliação de níveis de glicina+serina em dietas de frangos de corte com reduzido teor de proteína bruta
}

\author{
[Evaluation of glycine+serine levels in low crude protein diets for broiler chickens] \\ C.H.F. Vasconcellos ${ }^{1}$, D.O. Fontes ${ }^{2}$, L.J.C. Lara ${ }^{2}$, G.S.S. Corrêa ${ }^{3}$, M.A. Silva ${ }^{2}$, \\ T.Z.B. Vidal ${ }^{4}$, I.S. Fernandes ${ }^{4}$, J.S.R. Rocha ${ }^{4}$ \\ ${ }^{1}$ Universidade Federal de Viçosa - Florestal, MG \\ ${ }^{2}$ Escola de Veterinária - UFMG - Belo Horizonte, MG \\ ${ }^{3}$ Universidade Federal de Mato Grosso - Cuiabá, MT \\ ${ }^{4}$ Alunos de pós-graduação - Escola de Veterinária - UFMG - Belo Horizonte, MG
}

\begin{abstract}
RESUMO
O experimento foi conduzido em delineamento inteiramente ao acaso para avaliar os efeitos de diferentes níveis de glicina+serina (gli+ser) total em dietas de baixa proteína bruta (PB) sobre o desempenho e características de carcaça de frangos de corte de um a 21 dias de idade. Foram utilizadas 750 aves, distribuídas em cinco tratamentos, cinco repetições e 30 aves por unidade experimental. As dietas utilizadas continham $190 \mathrm{~g} / \mathrm{kg}$ de PB e níveis de gli+ser de 16,$7 ; 19,2 ; 21,7$ e 24,2g/kg; a dieta controle continha $230 \mathrm{~g} / \mathrm{kg}$ de PB. Avaliaram-se os efeitos dos níveis de glicina+serina sobre o desempenho e composição de carcaça. Os dados foram submetidos à análise de variância e os resultados obtidos com as dietas de baixos níveis proteicos com diferentes níveis de gli+ser foram comparados à dieta controle pelo teste de Dunnett. Os níveis de gli+ser apresentaram efeito linear sobre a conversão alimentar, ganho de peso e peso aos 21 dias, sendo o nível de $24,2 \mathrm{~g} / \mathrm{kg}$ de gli+ser com resultado semelhante à dieta controle. A redução proteica aumentou o conteúdo de extrato etéreo na carcaça.
\end{abstract}

Palavras-chave: frango, aminoácidos sintéticos, avaliação de carcaça, desempenho

\begin{abstract}
A completely randomized experimental design was carried out to evaluate the effects of total gly+ser levels in low crude protein diets on performance and body composition of male broiler chickens from 1 to 21 days of age. Seven hundred and fifty broiler chickens were used in each one of the production phases. The birds were randomly allotted to five treatments and five replicates. The diets contained $190 \mathrm{~g} / \mathrm{kg}$ crude protein $(C P)$ and total gly+ser levels of 16.7; 19.2; 21.7 and $24.2 \mathrm{~g} / \mathrm{kg}$; and a control diet with 230 $\mathrm{g} / \mathrm{kg}$ CP. The effect of glycine + serine levels on performance and body composition was evaluated. Data were subjected to analysis of variance and the results obtained with the diets of low crude protein levels with different levels of Gly + Ser were compared to the control diet by Dunnett's test. The gly+ser levels improved the feed linearly: weight gain ratio; weight gain and final weight. The broilers fed $24.2 \mathrm{~g} / \mathrm{kg}$ gly+ser diet showed a performance similar to broilers fed control diets. The carcass fat increased with CP reduction.
\end{abstract}

Keywords: broiler, performance; carcass; amino acids

\section{INTRODUÇÃO}

$\mathrm{Na}$ avicultura industrial, pequena diferença em aumento de produtividade ou redução de custos pode contribuir significativamente para o aumento da lucratividade da atividade. Atualmente existe grande pressão, não apenas para reduzir os custos de produção, mas também para reduzir desperdícios e eliminação de elementos poluentes, dentre os quais está o nitrogênio.

Recebido em 28 de agosto de 2013

Aceito em 2 de março de 2015

E-mail: carloshenrique@ufv.br 
A redução da eliminação de nitrogênio nas excretas das aves é facilmente conseguida quando se reduz o fornecimento de proteína na dieta. Por outro lado, a redução da proteína bruta das dietas nem sempre está associada a bom desempenho. Há relatos de diminuição do ganho de peso, piora da conversão alimentar e aumento do conteúdo de gordura na carcaça, indesejável pelos consumidores (Bregendahl et al.,2002; Sabino et al., 2004).

Alguns trabalhos têm demonstrado que, para se alcançar o nível de desempenho de aves alimentadas com dietas de alta proteína quando se trabalha com níveis proteicos reduzidos, há necessidade de suplementação com aminoácidos não essenciais, além dos essenciais (Kerr \& Kidd, 1999; Dean et al., 2006). A adição do aminoácido glicina em dietas de reduzido teor proteico tem efeito benéfico sobre as variáveis de desempenho. Dean et al. (2006) verificaram efeito linear da suplementação de diferentes níveis de glicina a dietas de baixa proteína sobre os parâmetros de desempenho em frangos de corte de 1 a 17 dias de idade. A suplementação de L-Glicina às dietas de baixa proteína permite melhor desempenho das aves que recebem a suplementação em comparação com as aves suplementadas apenas com aminoácidos essenciais (Dean et al., 2006). Por outro lado, essa suplementação de aminoácidos não essenciais em dietas de baixo nível proteico nem sempre permite desempenho equivalente ao obtido com aves alimentadas com dietas com níveis proteicos mais elevados. Desse modo, existem três pontos conflitantes: a necessidade de manter ótimo retorno econômico-produtivo da atividade avícola, a manutenção da qualidade e composição da carcaça de acordo com as exigências do consumidor $\mathrm{e}$, finalmente, a necessidade de se levar em conta o fator ambiental, diminuindo a excreção de nitrogênio.

Nesse sentido, objetivou-se avaliar o efeito de diferentes níveis de glicina+serina em dieta de baixo teor proteico sobre o desempenho e a composição de carcaça de frangos de corte machos de 1 a 21 dias de idade e comparar o desempenho dessas aves com aquelas alimentadas com uma dieta controle de alto nível proteico.

\section{MATERIAL E MÉTODOS}

As aves foram alojadas em galpão de alvenaria em piso de concreto, com 25 boxes de estrutura metálica $(2,0 \times 1,5 \mathrm{~m})$, com área total de $3 \mathrm{~m}^{2}$, forrados com cepilho de madeira, contendo comedouros semiautomáticos e bebedouros tipo copo de pressão na fase inicial e comedouro tubular e bebedouro pendular na fase de crescimento para cada unidade experimental. Foi utilizado um termômetro, colocado no interior do galpão, para registro diário da temperatura máxima e mínima.

Foram utilizados 750 pintos de corte, machos, da linhagem Ross, de um a 21 dias de idade, distribuídos aleatoriamente em cinco tratamentos e cinco repetições, com 30 aves/boxe e densidade de 10 aves $/ \mathrm{m}^{2}$. As aves foram vacinadas no incubatório contra a doença de Marek, e aos 12 dias de idade foram vacinadas contra a doença de Gumboro.

Até os 14 dias de idade, as aves receberam aquecimento artificial com uma lâmpada infravermelha por boxe. O programa de luz utilizado foi o seguinte: um a 14 dias, 24 horas de luz; 14 a 21 dias de idade, luz natural. A temperatura máxima e mínima aferidas durante $\mathrm{o}$ experimento variaram entre $28,4 \pm 7,0^{\circ} \mathrm{C}$ e $14,8 \pm 3,5^{\circ} \mathrm{C}$.

Foram utilizadas cinco dietas, sendo uma dieta testemunha com nível de proteína de $230 \mathrm{~g} / \mathrm{kg}$ e outras quatro com nível proteico de $190 \mathrm{~g} / \mathrm{kg}$ e níveis de glicina+serina total de 16,$7 ; 19,2 ; 21,7$ e $24,2 \mathrm{~g} / \mathrm{kg}$ (Tab. 1). Como material inerte, foi utilizado o caulim. Para evitar variações nos níveis de milho nas dietas, foi adicionado amido nas dietas de menor teor proteico. As dietas foram suplementadas com aminoácidos essenciais de acordo com as recomendações nutricionais de Rostagno et al. (2005). As aves receberam ração à vontade durante todo $\mathrm{o}$ período experimental. 
Avaliação de níveis...

Tabela 1. Composição alimentar e valores nutricionais calculados das dietas com níveis reduzidos de PB para frangos de corte de 1 a 21 dias de idade

\begin{tabular}{|c|c|c|c|c|c|}
\hline Ingredientes $(\mathrm{g} / \mathrm{kg})$ & $\mathrm{T} 1$ & $\mathrm{~T} 2$ & T3 & T4 & T5 \\
\hline Milho & 510,91 & 510,91 & 510,91 & 510,91 & 510,91 \\
\hline Farelo de soja & 408,10 & 307,9 & 302,6 & 249,4 & 249,4 \\
\hline Óleo de soja & 32,93 & 32,93 & 32,93 & 32,93 & 32,93 \\
\hline Amido & - & 55,82 & 55,82 & 55,82 & 55,82 \\
\hline Calcário & 8,96 & 8,95 & 8,95 & 8,95 & 8,95 \\
\hline Fosfato Bic. & 18,65 & 19,62 & 19,62 & 19,62 & 19,62 \\
\hline Sal comum & 5,07 & 5,12 & 5,12 & 5,12 & 5,12 \\
\hline Inerte & - & 34,8 & 32,36 & 29,83 & 27,31 \\
\hline Premix vit. Mineral $^{1}$ & 4,00 & 4,00 & 4,00 & 4,00 & 4,00 \\
\hline DL-Metionina & 2,40 & 3,53 & 3,53 & 3,53 & 3,53 \\
\hline L-Lisina & 0,78 & 4,08 & 4,08 & 4,08 & 4,08 \\
\hline L-Treonina & - & 1,63 & 1,63 & 1,63 & 1,63 \\
\hline L-Arginina & - & 0,94 & 0,94 & 0,94 & 0,94 \\
\hline L-Isoleucina & - & 0,35 & 0,35 & 0,35 & 0,35 \\
\hline L-Valina & - & 1,16 & 1,16 & 1,16 & 1,16 \\
\hline L-Glicina & - & - & 2,47 & 5,00 & 7,52 \\
\hline Total $(\mathrm{kg})$ & 1,00 & 1,00 & 1,00 & 1,00 & 1,00 \\
\hline \multicolumn{6}{|c|}{ Composição Calculada } \\
\hline Proteína Bruta (g/kg) & 230 & 190 & 190 & 190 & 190 \\
\hline EMA (Mcal/kg) & 2,980 & 2,980 & 2,980 & 2,980 & 2,980 \\
\hline Cálcio $(\mathrm{g} / \mathrm{kg})$ & 9,20 & 9,20 & 9,20 & 9,20 & 9,20 \\
\hline Fósforo Disp. (g/kg) & 4,60 & 4,60 & 4,60 & 4,60 & 4,60 \\
\hline Sódio & 2,20 & 2,20 & 2,20 & 2,20 & 2,20 \\
\hline Lisina Dig. (g/kg) & 12,10 & 12,10 & 12,10 & 12,10 & 12,10 \\
\hline Met.+Cis. Dig. (g/kg) & 8,60 & 8,60 & 8,60 & 8,60 & 8,60 \\
\hline Treonina Dig. (g/kg) & 7,80 & 7,80 & 7,80 & 7,80 & 7,80 \\
\hline Triptofano Dig. (g/kg) & 2,60 & 2,00 & 2,00 & 2,00 & 2,00 \\
\hline Isoleucina Dig. (g/kg) & 9,20 & 7,60 & 7,60 & 7,60 & 7,60 \\
\hline Valina Dig. $(\mathrm{g} / \mathrm{kg})$ & 9,70 & 8,90 & 8,90 & 8,90 & 8,90 \\
\hline Arginina Dig. (g/kg) & 14,90 & 12,60 & 12,60 & 12,60 & 12,60 \\
\hline Fenil.+Tir. Dig. (g/kg) & 17,90 & 16,10 & 16,10 & 16,10 & 16,10 \\
\hline Gli+Ser. Total $(\mathrm{g} / \mathrm{kg})$ & 21,00 & 16,70 & 19,20 & 21,70 & 24,20 \\
\hline
\end{tabular}

${ }^{1}$ Suplemento Vitamínico-mineral - composição por kg: vit. A (UI) 2.000.000; vit. D3 (UI) 375.000; vit. E (mg) 3.750; vit. B1 (mg) 250; vit. B2 (mg) 750; vit. B6 (mg) 500; vit. B12 (mcg) 3.750; niacina (mg) 6.250; ac. pantotênico (mg) 2.500; biotina (mg) 10; ac. fólico (mg) 125mg; colina (mg) 75.000; selênio (mg) 45; iodo (mg) 175; ferro $(\mathrm{mg})$ 12.525; cobre (mg) 2.500; manganês (mg) 19.500; zinco (mg) 13.750; avilamicina (mg) 15.000; narasin (mg) 12.250; BHT (mg) 500 .

Todas as aves foram pesadas com $01,07,14$ e 21 dias de idade. O ganho de peso foi calculado descontando-se o peso inicial dos pintos ao alojamento no $1^{\circ}$ dia.

O consumo de ração foi determinado, ao final do experimento, subtraindo-se a sobra da quantidade ofertada. A conversão alimentar foi obtida a partir do consumo médio de ração e do ganho médio de peso das aves ao final do experimento. Os valores da conversão alimentar foram corrigidos considerando-se a mortalidade ocorrida durante a semana, segundo Sakomura e Rostagno (2007).

O número de aves mortas foi registrado diariamente; a partir desses dados, determinou-se a porcentagem de mortalidade ( $\%$ MT) e posteriormente foi calculada a taxa de viabilidade (100 - \% MT).

Aos 21 dias de idade, uma ave de cada unidade experimental foi selecionada de forma aleatória e abatida. Perfazendo um total de cinco aves abatidas por tratamento; sendo que, para as 
análises estatísticas, cada ave foi considerada como uma parcela. Essas aves foram utilizadas para determinação da composição de carcaça. As carcaças, sem penas e sem as vísceras, foram moídas em moedor de carne e, após homogeneização, foram retiradas amostras que foram conservadas a $-12^{\circ} \mathrm{C}$.

Em razão da alta concentração de água e gordura na carcaça das aves, as amostras foram submetidas, inicialmente, à pré-secagem em estufa com ventilação forçada a $60^{\circ} \mathrm{C}$, por 96 horas, seguida de pré-desengorduramento pelo método a quente, por quatro horas, em extrator tipo soxhlet. As amostras pré-secas e prédesengorduradas foram então moídas e acondicionadas em potes de plástico, para análises posteriores. A água e a gordura retiradas durante o preparo inicial das amostras foram consideradas para correções dos valores das análises subsequentes. As análises de matéria seca, proteína bruta e extrato etéreo das amostras foram realizadas de acordo com recomendações descritas por Silva (1990).

O delineamento experimental utilizado foi inteiramente ao acaso com cinco tratamentos (dietas) e cinco repetições, sendo cada repetição composta de 30 aves para avaliação do desempenho zootécnico e uma ave por unidade experimental para avaliação da composição de carcaça. Os dados foram submetidos à análise de variância e os resultados obtidos com as dietas de baixos níveis proteicos com diferentes níveis de gli+ser foram comparados à dieta controle pelo teste de Dunnett. As análises dos dados foram feitas por meio do programa SAEG (Versão 9.1).
Para avaliação apenas dos efeitos dos níveis de Gli+Ser sobre o desempenho e composição de carcaça adotou-se o delineamento experimental com quatro tratamentos (eliminando-se o tratamento controle) e cinco repetições, sendo o número de aves por repetição o mesmo mencionado anteriormente para as características de desempenho e aquele para as características de carcaças. Nesses casos, os efeitos significativos dos níveis de gli+ser sobre a característica analisada foram calculados por análise de regressão, sendo os graus de liberdade dos fatores desdobrados em seus componentes lineares e quadráticos para a escolha do modelo de regressão que melhor representasse as observações obtidas com o presente estudo.

\section{RESULTADOS E DISCUSSÃO}

Observou-se que aves alimentadas com dietas contendo $24,2 \mathrm{~g} / \mathrm{kg}$ de gli+ser apresentaram desempenho semelhante ao das aves alimentadas com a dieta controle de alta PB para todas as variáveis de desempenho. Houve efeito linear dos níveis de gli+ser sobre o peso aos 21 dias de idade, ganho de peso e conversão alimentar nas dietas de baixa PB. Não houve efeito dos tratamentos sobre o consumo de ração (Tab. 2).

Alguns estudos demonstram que a redução do teor de PB não influencia o consumo de ração (Fergunson et al., 1998; Blair et al., 1999; Bregendahl et al., 2002; Sabino et al., 2004; Faria Filho et al., 2005). Corzo et al. (2005) também não observaram diferenças no consumo de ração de aves alimentadas com dietas de baixa PB suplementadas com aminoácidos não essenciais e essenciais.

Tabela 2. Desempenho de pintos de corte de 1 a 21 dias alimentados com diferentes níveis de gli+ser total e baixo teor de PB e comparação dos resultados com dieta controle de alta PB

\begin{tabular}{ccccc}
\hline $\begin{array}{c}\text { Níveis de Gli+Ser } \\
(\mathrm{g} / \mathrm{kg})^{*}\end{array}$ & $\begin{array}{c}\text { Peso aos 21 dias } \\
(\mathrm{kg})^{1}\end{array}$ & $\begin{array}{c}\text { Ganho peso aos } \\
\text { 21dias }(\mathrm{kg})^{2}\end{array}$ & $\begin{array}{c}\text { Consumo } \\
\text { ração }(\mathrm{kg})\end{array}$ & $\begin{array}{c}\text { Conversão } \\
\text { alimentar }^{3}\end{array}$ \\
\hline 16,7 & $0,8779 \mathrm{~b}$ & $0,8361 \mathrm{~b}$ & 1,04 & $1,243 \mathrm{~b}$ \\
19,2 & $0,9036 \mathrm{~b}$ & $0,8614 \mathrm{~b}$ & 1,03 & $1,195 \mathrm{~b}$ \\
21,7 & $0,9094 \mathrm{a}$ & $0,8670 \mathrm{a}$ & 1,03 & $1,188 \mathrm{~b}$ \\
24,2 & $0,9343 \mathrm{a}$ & $0,8919 \mathrm{a}$ & 1,04 & $1,166 \mathrm{a}$ \\
\hline $21,0($ Controle)** & $0,9326 \mathrm{a}$ & $0,8907 \mathrm{a}$ & 1,03 & $1,156 \mathrm{a}$ \\
\hline $\mathrm{dms}$ & 0,03 & 0,03 & - & 0,02 \\
\hline $\mathrm{CV}$ & 1,90 & 1,99 & 2,02 & 1,25 \\
\hline
\end{tabular}

Efeito linear dos níveis de GLI+SER. $(\mathrm{p}<0,01) \hat{\mathrm{Y}}=0,763310+0,00699511 \mathrm{X}\left(\mathrm{R}^{2}=0,95\right) ;{ }^{2}$ Efeito linear dos níveis de GLI+SER. $(p<0,01) \hat{\mathrm{Y}}=0,722364+0,00693217 \mathrm{X}\left(\mathrm{R}^{2}=0,95\right)$; ${ }^{3}$ Efeito linear dos níveis de GLI+SER. $(\mathrm{p}<0,01) \hat{\mathrm{Y}}=$ $1,39436-0,0096289 \mathrm{X}\left(\mathrm{R}^{2}=0,88\right)$. Médias seguidas de letras distintas nas colunas diferem estatisticamente em relação ao tratamento controle pelo teste Dunnett ( $<<0,05)$; *ração contendo $190 \mathrm{~g} / \mathrm{kg}$ de PB, ** ração contendo $230 \mathrm{~g} / \mathrm{kg}$ de PB. 
A partir dos resultados do presente trabalho, pode-se observar que a suplementação de glicina desempenha uma função importante em dietas de baixa proteína. Isso ocorre, provavelmente, devido a uma deficiência em aminoácidos não essenciais ou um imbalanço nutricional provocado pela redução da proteína dietética. A adição de glicina, possivelmente, contribuiu para um melhor ajuste nutricional, melhorando o desempenho das aves. A literatura também tem mostrado a importância da glicina na melhoria do desempenho de aves alimentadas com dietas de baixa PB.

Dean et al. (2006) avaliaram os efeitos da adição de aminoácidos essenciais e glicina sobre o desempenho de frangos de corte do nascimento aos 17 dias de idade. As aves que foram alimentadas com dietas de baixa PB suplementadas com aminoácidos essenciais mais $20,7 \mathrm{~g} / \mathrm{kg}$ de gli+ser tiveram desempenho semelhante ao das aves alimentadas com dieta de alto teor proteico. Os autores observaram que a adição de glicina a dietas de baixa PB $(160 \mathrm{~g} / \mathrm{kg})$ melhorou linearmente a conversão alimentar, e para máximo desempenho recomendou-se o nível de 24,4 g/kg de gli+ser total.

De modo semelhante, Corzo et al. (2004) avaliaram o desempenho de frangos de corte entre a segunda e a terceira semanas de idade alimentados com dieta contendo $180 \mathrm{~g} / \mathrm{kg}$ de PB e diferentes níveis de glicina. Não concordando com os resultados encontrados neste trabalho, Corzo et al. (2004) encontraram resposta quadrática dos níveis de glicina, sendo os melhores resultados para crescimento $\mathrm{e}$ conversão alimentar estimados para níveis de 17,6 e $18,0 \mathrm{~g} / \mathrm{kg}$ de gli+ser, respectivamente. Segundo os autores, a glicina precisa ser considerada como um nutriente limitante, especialmente em dietas de baixa $\mathrm{PB}$ ao se utilizarem apenas ingredientes vegetais na formulação das dietas.

Bernardino et al. (2012), trabalhando com diferentes relações treonina:lisina com ou sem a suplementação de glicina, verificaram que a suplementação de glicina é essencial para melhorar o desempenho de frangos de corte de 8 a 21 dias. Também utilizando glicina na alimentação de frangos de corte, Vasconcellos et al. (2011) observaram melhoria na conversão alimentar de aves que receberam dietas de baixa proteína na fase de crescimento.

Corzo et al. (2005) também estudaram a adição de aminoácidos essenciais e não essenciais em dietas de frangos de corte e verificaram que a suplementação de aminoácidos não essenciais em dietas de baixa proteína é necessária para que as aves tenham o mesmo desempenho daquelas alimentadas com dietas de alto nível proteico. Hussein et al. (2001), da mesma forma, concluíram que é importante a suplementação extra de aminoácidos sintéticos em dietas de menor teor de proteína bruta.

Não houve efeito dos níveis de glicina sobre a viabilidade. Comparando-se as dietas de baixo teor de PB com diferentes níveis de glicina com a dieta controle de alto teor proteico, também não foram observadas diferenças sobre essa variável (Tab. 3).

Tabela 3. Viabilidade (\%) de pintos de corte de 1 a 21 dias alimentados com diferentes níveis de gli+ser total e baixo teor de PB e comparação dos resultados com dieta controle de alta PB

\begin{tabular}{ccc}
\hline Níveis de Gli+Ser $(\mathrm{g} / \mathrm{kg})^{*}$ & VV $(\%)$ \\
\hline 16,7 & 99,67 & \\
19,2 & 99,33 & 2,24 \\
21,7 & 99,33 & \\
24,2 & 99,33 & \\
\hline Controle** & 98,00 & \\
\hline Significância & $\mathrm{ns}$ & \\
\hline
\end{tabular}

\footnotetext{
${ }^{\mathrm{ns}}$ não significativo pelo teste de Dunnett $(\mathrm{P}>0,05)$; *dieta basal contendo $190 \mathrm{~g} / \mathrm{kg}$ de PB; ** dieta basal contendo $230 \mathrm{~g} / \mathrm{kg}$ de $\mathrm{PB}$.
}

Não houve efeito dos diferentes níveis de gli+ser em nenhuma das variáveis avaliadas $(\mathrm{P}>0,05) \mathrm{em}$ relação à composição de carcaça nas dietas com nível reduzido de proteína bruta. Porém, ao comparar os dados com os resultados obtidos com a dieta de alto teor proteico, observou-se aumento do teor de extrato etéreo (EE) nas dietas com menor nível de PB (Tab. 4). 
Tabela 4. Comparação da composição percentual na matéria seca de carcaças de frangos de corte aos 21 dias de idade alimentados com diferentes níveis de gli+ser total com baixos níveis de PB em relação à dieta controle

\begin{tabular}{ccccc}
$\begin{array}{c}\text { Gli+Ser } \\
(\mathrm{g} / \mathrm{kg})^{*}\end{array}$ & $\begin{array}{c}\mathrm{MS} \\
(\mathrm{g} / \mathrm{kg})\end{array}$ & $\begin{array}{c}\mathrm{PB} \\
(\mathrm{g} / \mathrm{kg})\end{array}$ & $\begin{array}{c}\mathrm{EE} \\
(\mathrm{g} / \mathrm{kg})\end{array}$ & $\begin{array}{c}\mathrm{MM} \\
(\mathrm{g} / \mathrm{kg})\end{array}$ \\
\hline 16,7 & $307,2 \mathrm{a}$ & $169,5 \mathrm{~b}$ & $109,7 \mathrm{~b}$ & 25,7 \\
19,2 & $297,0 \mathrm{a}$ & $176,6 \mathrm{a}$ & $101,5 \mathrm{~b}$ & 25,8 \\
21,7 & $312,9 \mathrm{~b}$ & $165,1 \mathrm{~b}$ & $119,4 \mathrm{~b}$ & 25,4 \\
24,2 & $294,0 \mathrm{a}$ & $173,6 \mathrm{a}$ & $100,8 \mathrm{~b}$ & 26,7 \\
\hline $21,0($ Controle)** & $295,9 \mathrm{a}$ & $178,0 \mathrm{a}$ & $82,5 \mathrm{a}$ & 26,5 \\
\hline CV $(\%)$ & 2,95 & 3,29 & 7,90 & 12.04 \\
\hline
\end{tabular}

Médias seguidas de letras distintas nas colunas diferem estatisticamente em relação ao tratamento controle pelo teste Dunnet $(\mathrm{P}<0,05)$; CV: Coeficiente de Variação; *ração basal contendo $190 \mathrm{~g} / \mathrm{kg}$ de PB; **ração basal contendo $230 \mathrm{~g} / \mathrm{kg}$ de $\mathrm{PB}$.

Não houve efeito dos tratamentos sobre os conteúdos de matéria mineral (MM). Em relação aos teores de matéria seca (MS), a dieta de alto teor proteico apresentou mesmo teor de MS nas carcaças que as dietas de baixa proteína bruta que continham 16,7; 19,2 e 24,2g/kg de gli+ser. O tratamento com $21,7 \mathrm{~g} / \mathrm{kg}$ de gli+ser apresentou maior teor de MS que o tratamento de alto nível proteico.

O conteúdo de PB na carcaça dos frangos dos tratamentos de 16,7 e $21,7 \mathrm{~g} / \mathrm{kg}$ de gli+ser foi menor que do tratamento controle. Diferenças nos teores de PB depositados na carcaça de frangos que receberam dietas com diferentes níveis de PB também foram relatados por Gonzalez-Esquera e Leeson (2005) e Faria Filho et al. (2004), citados por Furlan et al. (2004), que observaram aumento na deposição de proteína na carcaça quando as aves consumiram dietas mais ricas em proteína.

Por outro lado, teores semelhantes de proteína na carcaça com diminuição dietética de proteína foram encontrados por Braga (1999) e Bregendahl et al. (2002). Conforme relatos de Leeson \& Summers (1997), existe pequena variação na deposição proteica com a variação da PB da dieta. Também de acordo com Furlan et al. (2004), a deposição de aminoácidos na carcaça é pré-estabelecida geneticamente, não podendo ser modificada pela dieta.

A diminuição dos níveis de PB geralmente leva a aumento na quantidade de gordura na carcaça. Da mesma forma que ocorreu neste experimento, aumento dos níveis de gordura na carcaça com redução dos teores de $\mathrm{PB}$ da dieta têm sido observados com frequência nos trabalhos científicos (Kerr et al., 1995; Cromwell et al., 1996; Tuitoek et al., 1997; Braga, 1999; Costa et al., 2001; Bregendahl et al., 2002; Silva et al., 2003). Isso deve-se ao fato de haver economia de energia quando não se tem excesso de nitrogênio para ser eliminado. Outro fator, segundo Costa et al. (2001), é o catabolismo de aminoácidos nas dietas de baixa PB em razão do imbalanço de aminoácidos.

\section{CONCLUSÕES}

Os níveis de gli+ser apresentaram efeito linear sobre a conversão alimentar, ganho de peso e peso aos 21 dias. O nível de $24,2 \mathrm{~g} / \mathrm{kg}$ de gli+ser em dieta de reduzido teor proteico apresentou resultado semelhante ao da dieta controle. A redução proteica aumentou o conteúdo de extrato etéreo na carcaça.

\section{REFERÊNCIAS}

BERNARDINO, V.M.P.; ALBINO, L.F.T.; ROSTAGNO, H.S. et al. Suplementação de glicina para pintos de corte submetidos a dietas com diferentes relações treonina:lisina digestíveis. Rev. Bras. Saúde Prod. Anim., v.13, p.173-180, 2012

BLAIR, R.; JACOB, J.P.; IBRAHIM, S. et al. A quantitative assessment of reduced protein diets and supplements to improve nitrogen utilization. J. Appl. Poul. Res., v.8, p.25-47, 1999.

BRAGA, J.P. Proteína ideal para frangos de corte: efeito sobre o desempenho e composição de carcaça. 1999. 25f. Dissertação (Mestrado em Zootecnia) Escola de Veterinária, Universidade Federal de Minas Gerais, Belo Horizonte, MG. 
BREGENDAHL, K.; SELL, J.L.; ZIMMERMAN, D.R. Effect of low-protein diets on growth performance and body composition of broiler chicks. Poult. Sci., v.81. p.1156-1167, 2002.

CORZO, A.; KIDD, M.T.; BURNHAM, D.J. et al. Dietary glycine needs of broiler chicks. Poult. Sci., v.83, p.1382-1384. 2004.

CORZO, A.; FRITTS, C.A.; KIDD, M.T. et al. Response of broiler chicks to essential and nonessential amino acid supplementation of low crude protein diets. Anim. Feed Sci. Technol., v.118, p.319$327,2005$.

COSTA, F.G.P.; ROSTAGNO, H.S.; ALBINO, L.F.T. et al. Níveis dietéticos de proteína bruta para frangos de corte de 1 a 21 e 22 a 42 dias de idade. Rev. Bras. Zootec., v.30, p.1498-1505, 2001.

CROMWELL, G.L.; LINDERMANN, M.D.; PARKER, G.R. et al. Low protein, amino acid supplemented diets for growing-finishing pigs. $J$. Anim. Sci., v.74. p.174, 1996.

DEAN, D.W.; BIDNER, T.D.; SOUTHERN, L.L. Glycine supplementation to low protein, amino acidsuplemented diets supports optimal performance of broiler chicks. Poult. Sci., v.85, p.288-296, 2006.

FARIA FILHO, D.E.; ROSA, P.S.; VIEIRA, B.S.et al. Protein levels and environmental temperature effects on carcass characteristics, performance, and nitrogen excretion of broiler chickens from 7 to 21 days of age. Rev. Bras. Cienc. Avícola, v.7, p.247-253, 2005.

FERGUSON, N.S.; GATES, R.S.; TARABA, J.L. et al. The effect of dietary protein and phosphorus on ammonia concentration and litter composition in broilers. Poult. Sci., v.77, p.1085-1093, 1998.

FURLAN, R.L.; FARIA FILHO, D.E.; ROSA, P.S. et al. Does low-protein diet improve broiler performance under heat stress conditions? Rev. Bras. Cienc. Avícola, v.6, p.71-79, 2004.

GONZALEZ-ESQUERRA, R.; LEESON, S. Effects of acute versus chronic heat stress on broiler response to dietary protein. Poultry Science, v.84. p.1562-1569, 2005.

HUSSEIN, A.S.; CANTOR, A.H.; PESCATORE, A.J. Effect of low protein diets with amino acid supplementation on broiler growth. J. Appl. Poult. Res., v.10, p.354-362, 2001.
KERR B. J.; KIDD, M. T. Amino acid supplementation of low - protein broiler diets 2 . Formulation on an ideal amino acid basis. J. Appl. Poult. Res., v.8, p.310-320, 1999.

KERR, B.J.; McKEITH, F.K.; EASTER, R.A. Effect of performance and carcass characteristics of nursery to finisher pigs fed reduced crude protein, amino acidsupplemented diets. J. Anim. Sci., v.73, p.433-440, 1995.

LEESON, S.; SUMMERS, D.J. Commercial poultry nutrition. 2.ed. Guelph, Ontario. Canada: University Books; 1997. 350p.

ROSTAGNO, H.S., ALBINO, L.F.T. ; DONZELE, J.L. et al. Tabelas brasileiras para aves e suínos: composição de alimentos e exigências nutricionais. Viçosa: UFV, 2005. 186p.

SABINO, H.F.N.; SAKOMURA, N.K.; NEME, R. et al. Níveis protéicos na ração de frangos de corte na fase de crescimento. Pesqui. Agropecu. Bras., v.39, p.407-412, 2004.

SAKOMURA, N.K.; ROSTAGNO, H.S. Métodos de pesquisa em nutrição de monogástricos. Jaboticabal: Funep, 2007. 283p.

SILVA, D.J. Análise de alimentos: métodos químicos e biológicos. 2.ed. Viçosa, MG: UFV, 1990. 166 p.

SILVA, J.H.V.; ALBINO, L.F.T.; NASCIMENTO, A.H. Estimativas da composição anatômica da carcaça de frangos de corte com base no nível de proteína da ração e peso da carcaça. Rev. Bras. Zootec., v.32, p.344-352, 2003.

TUITOEK, K.; YOUNG, L.G.; de LANGE, C.F.M. et $a l$. The effect of reducing excess dietary amino acids on growing-finishing pig performance: an evaluation of the ideal protein concept. J. Anim. Sci., v.75, p.1575-1583, 1997.

VASCONCELLOS, C.H.F.; FONTES, D.O.; SILVA, M.O. et al. Teores de glicina+ serina total em dietas de baixa proteína bruta para de frangos de corte de 22 a 35 dias de idade. Arq. Bras. Med. Vet. Zootec., v.63, p.641-648, 2011. 